\title{
PA 07-6-2657 research to intervention: preventing fire and burn safety education initiative for primary school children in Malaysia
}

\begin{abstract}
Burn injuries are a serious public health problem globally and Malaysia in not exceptional to it where we lose one child every fourteen days from a burn injury which is preventable. The aim of this exercise was to understand the magnitude of the Fire and Burn Injury problem and followed by developing and implementing an intervention program as a solution. The study was a crosssectional survey among 640 parents of children attending primary schools (children age 7-12) in Sentul, Kuala Lumpur. A total of 9 primary schools out of 558 were chosen for this study. Questionnaires for the parents were given and collected through the identified children. Prevalence of fire in the past two years were $6.4 \%$ and burn injury among children were alarmingly standing at $54 \%$. The top five frequent occurring cause of burn injuries reported by the parents for their children were: touching hot utensils $(24.4 \%)$, hot iron $(21.7 \%)$, hot water heater $(17.2 \%)$, motorcycle hot exhaust pipe (16.7\%) and playing with fire crackers (14.4\%). In conclusion, an educational intervention program on preventing fire and burn was developed based on the top five causes of burn and also focusing on what need to be done in an event of fire as well as injury. The four module education program was intervened to the 6000 primary school children for a duration of 180 min combining both classroom teaching session and field demonstration on how to escape and fight fire with the assistance from Fire and Rescue Department as our program partner. This initiative has a potential policy implication where this pilot intervention program if succeeds, it is recommended the program to be scaled up for the betterment and benefit for more children.
\end{abstract}

Keyword: Burn injuries; Preventable; Educational intervention program on preventing fire 